\title{
Fe(III)-Citrate-Complex-Induced Photooxidation of 3-Methylphenol in Aqueous Solution
}

\author{
N. Seraghni, S. Belattar, Y. Mameri, N. Debbache, and T. Sehili \\ Laboratoire des Sciences et Technologie de l'Environnement (LSTE), Département de Chimie, Faculté des Sciences Exactes, \\ Université de Mentouri, Constantine, Algeria \\ Correspondence should be addressed to N. Debbache, nadradebbache@yahoo.fr
}

Received 29 October 2011; Revised 3 January 2012; Accepted 4 January 2012

Academic Editor: Peter Robertson

Copyright ( $\odot 2012$ N. Seraghni et al. This is an open access article distributed under the Creative Commons Attribution License, which permits unrestricted use, distribution, and reproduction in any medium, provided the original work is properly cited.

The photodegradation process of $\mathrm{m}$-cresol (3-methylphenol), induced by $\mathrm{Fe}$ (III)-Cit complex, was investigated upon irradiation at $365 \mathrm{~nm}$ in natural water. The composition and photochemical properties of Fe(III)-Cit complex were studied by UV-Visible absorption spectrophotometer for optimizing the stoichiometry of the complex and photolysis under irradiation at $365 \mathrm{~nm}$, respectively. A dark investigation of the system was performed before studying the photochemical behavior. The photooxidation efficiencies of $\mathrm{m}$-cresol were dependent on the $\mathrm{pH}$ value, optimized at $\mathrm{pH} 2.86$, oxygen, initial concentrations of $\mathrm{Fe}$ (III)-Cit complex, and m-cresol. Additionally, to look into the mechanism of m-cresol degradation using Fe(III)-Cit, tertiobutanol alcohol was used as scavenger for hydroxyl radicals and the result suggested that hydroxyl radical attack was the main pathway of $\mathrm{m}$-cresol degradation. Besides, oxygen can enhance the photolysis of Fe(III)-Citrate complex by trapping the electron on the carbon centered radical formed after the photoredox process. Then $\mathrm{O}_{2}^{--}$formed reacts rapidly leading finally to formation of $\bullet \mathrm{OH}$ radical. In absence of oxygen, less reactive species are formed; consequently the disappearance of $\mathrm{m}$-cresol was strongly inhibited. Our work shows that the presence of $\mathrm{Fe}$ (III)-Citrate complex could have a considerable impact on the fate of organic pollutant in aquatic environment.

\section{Introduction}

Advanced oxidation technologies (AOTs) are innovative methods for water treatment, extremely useful in the case of substances resistant to conventional technologies $[1,2]$. Due to its ability to generate ${ }^{\circ} \mathrm{OH}$ radicals, the photocatalysis of complexing agents is a promising new technique for removal pollutant. Although thermally stable, the use of complex on photocatalyst is recommended due to their presence in natural aquatic systems. It was reported that light irradiation of $\mathrm{Fe}$ (III) complexes with dissolved organic matter (DOM) could produce both $\mathrm{Fe}(\mathrm{II})$ by the ligand-to-metal charge transfer (LMCT) reactions and $\mathrm{H}_{2} \mathrm{O}_{2}$ through the reduction of $\mathrm{O}_{2}$ by photoexcited DOM [3-5]. The efficiency of this photocatalytic process has already been observed to remove compound from water. Citric acid $(\mathrm{C}(\mathrm{OH})(\mathrm{COOH})$ $\left(\mathrm{CH}_{2} \mathrm{COOH}\right)$ 2, 2-hydroxy-propane-1,2,3-tricarboxylic acid, Cit) is used as model compound of several natural systems because of its presence in plants and soils. It is an $\mathrm{Fe}(\mathrm{III})$ transport agent in biological systems [6], a frequent domestic and industrial chelating agent used in the food industry and in detergents [7], and it is often used as a reducing agent in photolytic and photocatalytic systems [7]. Fe(III) is easily complexed by citric acid giving Fe(III)-Cit. The literature report that $\mathrm{Fe}(\mathrm{III})$-Cit is stable to near UV-Visible [8], but it is decomposed by photolysis below $242 \mathrm{~nm}$ [9-12]. In the case of Fe(III)-Cit, UV and blue-light promote an efficient photolysis with $\mathrm{Fe}$ (II) formation and oxidation of the ligand [13-15]. The reported final products are acetone, carbon dioxide, and acetonedicarboxylic acid (3-oxoglutaric acid, 3-OGA), while acetic and acetoacetic acids were found as intermediates [13].

Thus, the literature reports that the presence of carboxylic acids such as oxalic, citric, or tartaric acids with $\mathrm{Fe}$ (III) and UVA radiation improves the water elimination rates of organics such as dyes [16-18], herbicides [19-21], pesticides $[22,23]$, surfactants $[24,25]$, benzene [26], phenols [27, 28], and other hydrocarbons [29], among other 
[30]. During the photochemical reaction of Fe(III)-carboxylate complexes, dissolved $\mathrm{Fe}(\mathrm{II})$ and $\mathrm{Fe}(\mathrm{III})$ species, the superoxide and hydroxyl radicals $\left(\mathrm{O}_{2}^{--},{ }^{\bullet} \mathrm{OOH}\right)$, and hydrogen peroxides $\left(\mathrm{H}_{2} \mathrm{O}_{2}\right)$ are formed as the key intermediates; the hydroxyl radical ${ }^{\circ} \mathrm{OH}$ is also produced.

It is known that organic pollutants were attacked by hydroxyl radical and mineralized efficiently in above photochemical system.

$\mathrm{Fe}$ (III)-Cit photolysis has been studied in detail by different authors [7, 20,31]. Main steps of free radical generation can be represented as in the following reactions [7]:

$$
\begin{gathered}
\mathrm{Fe}(\mathrm{III})-\mathrm{Cit} \stackrel{h v}{\longrightarrow} \mathrm{Fe}(\mathrm{II})+{ }^{\bullet} \mathrm{Cit} \\
\cdot \mathrm{Cit} \longrightarrow \mathrm{HO}-{ }^{\cdot} \mathrm{CR}_{2}+\mathrm{CO}_{2} \\
\mathrm{HO}-{ }^{\cdot} \mathrm{CR}_{2}+\mathrm{Fe}(\mathrm{III}) \longrightarrow \mathrm{R}_{2} \mathrm{C}=\mathrm{O}+\mathrm{H}^{+}+\mathrm{Fe}(\mathrm{II}) \\
\mathrm{HO}-{ }^{\cdot} \mathrm{CR}_{2}+\mathrm{O}_{2} \longrightarrow \mathrm{R}_{2} \mathrm{C}=\mathrm{O}+\mathrm{H}^{+}+\mathrm{O}_{2}{ }^{--} \\
\mathrm{R}_{2} \mathrm{C}=\mathrm{O}+2 \mathrm{Fe}(\mathrm{III}) \longrightarrow \mathrm{R}_{2}^{\prime} \mathrm{C}=\mathrm{O}+2 \mathrm{CO}_{2} \\
2 \mathrm{H}^{+}+2 \mathrm{O}_{2}{ }^{-} \longrightarrow \mathrm{H}_{2} \mathrm{O}_{2}+\mathrm{O}_{2} \\
\mathrm{H}_{2} \mathrm{O}_{2}+\mathrm{Fe}(\mathrm{II}) \longrightarrow \mathrm{Fe}(\mathrm{III})+{ }^{\bullet} \mathrm{OH}+{ }^{-} \mathrm{OH} \\
\mathrm{Fe}(\mathrm{OH})^{+2}+h \nu \longrightarrow \mathrm{Fe}^{+2}+\cdot \mathrm{OH},
\end{gathered}
$$

where $\mathrm{R}=-\mathrm{CH}_{2} \mathrm{COOH}$ and $\mathrm{R}^{\prime}=-\mathrm{CH}_{3}$.

The aims of this study were as follows: (1) characterizing the physicochemical and photochemical properties of $\mathrm{Fe}(\mathrm{III})$-Cit complex, (2) studying the photochemical degradation of $\mathrm{m}$-cresol induced by $\mathrm{Fe}$ (III)-Cit system, and examining several factors that controlled the kinetics of $\mathrm{m}$ cresol degradation.

\section{Experimental}

2.1. Reagents. All reagents were of the purest commercially available grade and used without further purification. The solutions were prepared using ultrapure water. Ferric perchlorate nonahydrate $\left(\mathrm{Fe}\left(\mathrm{ClO}_{4}\right)_{3}, 9 \mathrm{H}_{2} \mathrm{O}\right)$, Carlo Erba, pur and citric acid (Synth) was used as ligand. 3-Methylphenol ( $\mathrm{m}$-cresol) was purchased by Prolabo (purity greater than 99\%). Hydrochloric Acid, Merck, 25\%, tertiobutanol, Prolabo, 99\%, acetate sodium (99\%), and acetic acid (99.5\%) provided by Panreac, sodium hydroxide, Carlo Erba 98\%, 1,10-phenantroline, Fluka, $>99 \%$. The $\mathrm{pH}$ was measured with a $\mathrm{pH}$-meter type (HANNA) equipped with a combined glass electrode. The $\mathrm{pH}$ meter is first calibrated with buffer solutions $(\mathrm{pH}=4, \mathrm{pH}=7$, and $\mathrm{pH}=10)$ and was adjusted when necessary by using $\mathrm{HCl}$ acid $0.1 \mathrm{M}$ or $\mathrm{NaOH} 0.1 \mathrm{M}$.

2.2. Preparation of $\mathrm{Fe}(\mathrm{III})$-Citrate Complex. A stock solution containing $13.0 \mathrm{mM}$ citric acid was prepared with deionized water, and $2 \mathrm{~mL}$ of this stock solution was diluted to $50 \mathrm{~mL}$. Stock solutions were prepared containing $13.0 \mathrm{mM}$
$\left(\mathrm{Fe}\left(\mathrm{ClO}_{4}\right)_{3}, 9 \mathrm{H}_{2} \mathrm{O}\right)$. The solution was maintained under anoxic conditions until further use. Equimolar Fe(III)-Cit complexes were prepared by adding $2 \mathrm{~mL}$ each of $13.0 \mathrm{mM}$ citric acid and $\left(\mathrm{Fe}\left(\mathrm{ClO}_{4}\right)_{3}, 9 \mathrm{H}_{2} \mathrm{O}\right)$ solution and diluted to a final concentration of $0.52 \mathrm{mM}$. The ionic strength of the solution was not controlled, and the $\mathrm{pH}$ was adjusted to 6.1 by $\mathrm{NaOH}$ $0.1 \mathrm{M}$ [32]. All complexes were prepared under low light and kept in the dark to prevent photodecomposition.

2.3. Photodegradation Experiments. The irradiation experiments were performed in a Pyrex cylindrical reactor with a double envelope with about $3 \mathrm{~cm}$ in diameter, open to air, was placed in the centre of the cylindrical stainless steel container. The photoreactor was exposed to the radiation sources composed of one low pressure mercury UV lamp type Philips HPW 125, (UV-A, $\lambda_{\max }=365 \mathrm{~nm}$ ).

The solution (usually $50 \mathrm{~mL}$ ) was continuous magnetically stirred with a magnetic bar during irradiation to insure its homogeneity. Control experiments showed that no degradation of m-cresol occurred in Fe(III)-Cit complex without irradiation in this reactor.

When necessary, reaction solutions were deaerated or oxygenated by purging with nitrogen or oxygen before irradiation. The purging time for the solution is $30 \mathrm{~min}$.

2.4. Analysis. At different time intervals during the irradiation, samples were collected and analyzed by HPLC. m-cresol was monitored at $272 \mathrm{~nm}$ by HPLC (Shimadzu) equipped with a controller model SCL-10A VP, photodiode-array UVVis detector model SPD-M10A VP and two pumps model LC 8A. The system is controlled by software "Class VP5 for storing and processing of chromatograms." The mobile phase was acetonitrile/water mixture $(20 / 80, \mathrm{v} / \mathrm{v})$ at a flow rate of $1.0 \mathrm{mLmin}^{-1}$ using Supelco, C18 column $(5 \mu \mathrm{m}, 250 \mathrm{~mm} \times$ $4.6 \mathrm{~mm}$ i.d). The absorption spectra of solutions have been recorded on a spectrophotometer Unicam "He $\lambda$ ios $\alpha$ " connected to a computer for the storage and treatment of spectra.

$\mathrm{Fe}$ (II) concentration was determined by the method of Zuo [33] with o-phenantroline by measuring the absorbance at $510 \mathrm{~nm}$ of the complex (the molar absorption coefficient: $\left.11040 \mathrm{M}^{-1} \cdot \mathrm{cm}^{-1}[30]\right)$.

\section{Results and Discussion}

3.1. Spectral Properties of Complex. The UV-visible absorption spectra of citric acid, $\mathrm{Fe}(\mathrm{III})$ and $\mathrm{Fe}$ (III)-Cit complex were shown in Figure 1. The citric acid does not absorb significantly beyond $230 \mathrm{~nm}$. The absorption spectrum of $\mathrm{Fe}$ (III) $0.52 \mathrm{mM}$ in aqueous solution shows a strong absorption band at $297 \mathrm{~nm}$. At the same time, we note that the absorbance of $\mathrm{Fe}(\mathrm{III})$-Cit is low in the visible; however by nearer to the short wavelengths it becomes important. Furthermore a shoulder is observed around $226 \mathrm{~nm}$ for Fe(III)Cit. It was obviously interpreted by the fact that Fe(III) was complexed by citric acid in the solution.

Determination of Stability Constant of the Fe(III)-Cit Complex. The determination of stability constant is performed 


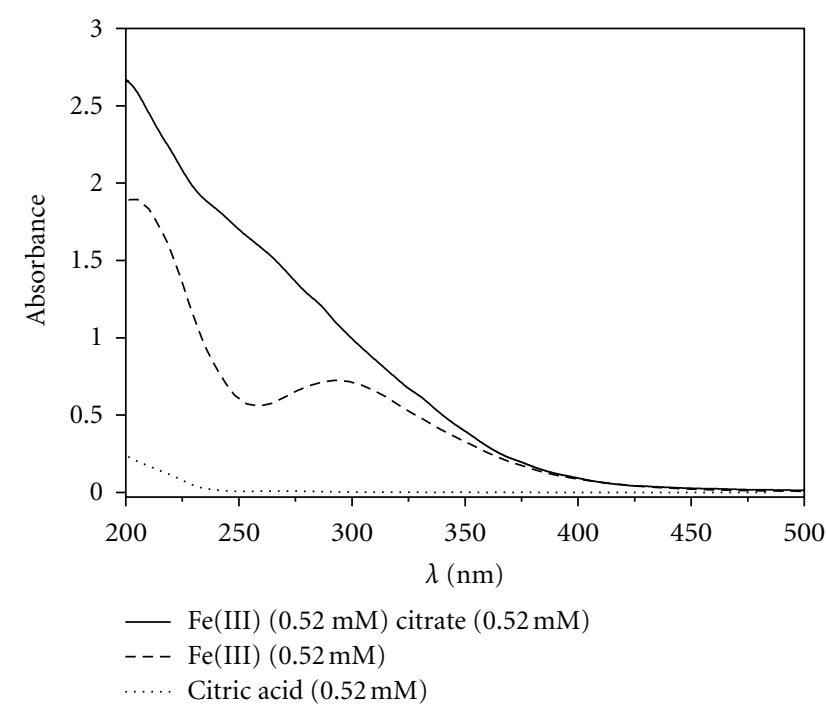

FIgURE 1: UV-Visible absorption spectra of citric acid $0.52 \mathrm{mM}$, $\mathrm{Fe}$ (III) $0.52 \mathrm{mM}$, and $\mathrm{Fe}$ (III)-Cit complex, $\mathrm{pH}=6.1$.

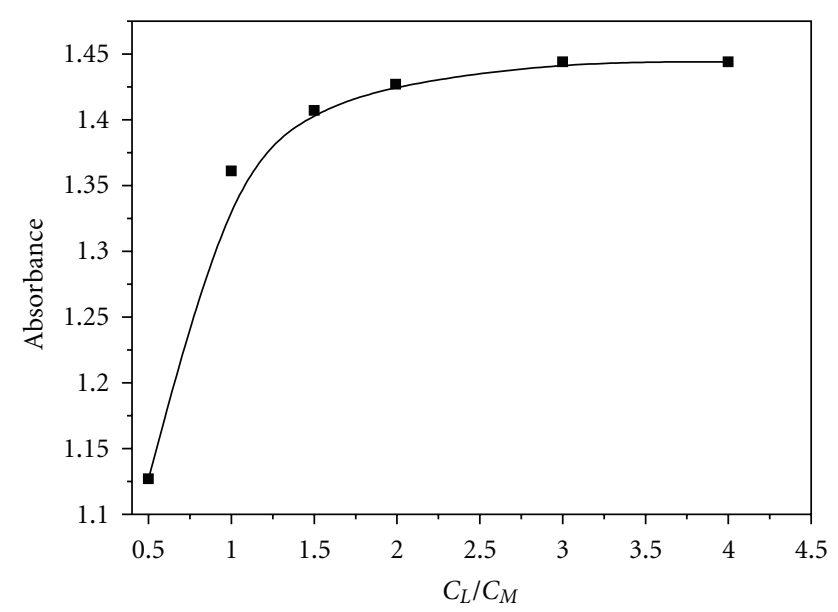

Figure 2: Variation of the absorbance at $272 \mathrm{~nm}$ of $\mathrm{Fe}(\mathrm{III})$-Cit as a function of the ratio $C_{L} / C_{M},[\mathrm{Fe}(\mathrm{III})]=0.3 \mathrm{mM}, \mathrm{pH}=6.1$.

using the method of saturation [34]. This method was based on the spectrophotometric analysis. The concentration of metal ions $\left(C_{M}\right)$ in aqueous solution was kept constant and the concentration of the relative acid $\left(C_{L}\right)$ was increased in the experiment. The volume of the solution is kept constant.

As shown in Figure 2, the absorbance of the aqueous solution was set as $y$-axis; the corresponding ratio of $C_{L} / C_{M}$ was set as $x$-axis. Then the ratio of $C_{L} / C_{M}$ represents the composition of the complex.

This absorbance becomes stable, which indicates that metal ions are totally complexed by the acid. The stoichiometry and stability constants of complex are deduced from following equation [35]:

$$
\log \left(\frac{A_{i}}{A_{\max }-A_{i}}\right)=n \log C_{L}+\log \beta
$$

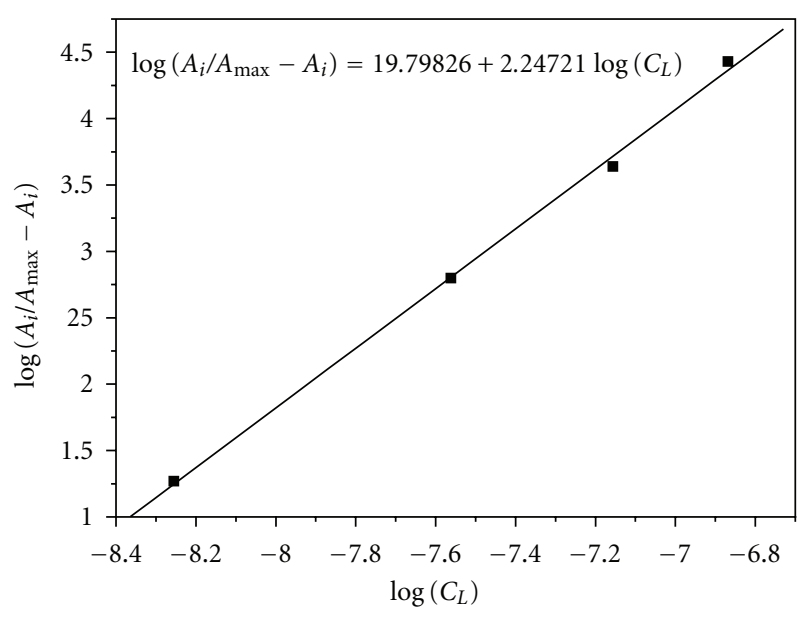

Figure 3: $\log \left(A_{i} / A_{\max }-A_{i}\right)$ as a function of $\log C_{L}$.

Where $A_{i}$ is absorbance corresponding to the growing part of the saturation curve. $A_{\max }$ is absorbance corresponding to the level of the saturation curve. $\beta$ is constant of stability. $C_{L}$ is concentration of ligand for each $A_{i} . n$ is stoichiometric ratio $\left(C_{L} / C_{M}\right)$ (Figure 3 ).

The stoichiometry of the complex that corresponds to the ratio $\left(C_{L} / C_{M}\right)$ is estimated at $2: 1$. The value of $\log \beta$ is deduced from the graph $(\log \beta=19.8) . \beta=6.3 \times 10^{19}$.

\subsection{Photochemical Properties of Fe(III)-Cit Complex}

3.2.1. Photolysis of Fe(III)-Cit Complex. Photolysis of Fe(III)Cit complex $(0.3 \mathrm{mM})$ is studied in the aqueous solution under irradiation at $365 \mathrm{~nm}$. The UV-visible evolution of the aqueous solution during irradiation was reported in Figure 4 . Isosbestic points appear very clearly at $354 \mathrm{~nm}$. It indicates that this complex is easily photolysed and provided the possibility for the formation of excited state complexes and further generated many kinds of radicals [36].

Analysis by HPLC. In aqueous solutions, the Fe(III)-Cit complex after irradiation can undergo LMCT, which produced Fe(II) and consumed citrate. As is shown in Figure 5, the photolysis efficiency of the Fe(III)-Cit in $50 \mathrm{~min}$ is $90 \%$ and the initial rate $V_{0 \text { (FeCit })}=1.4 \times 10^{-6} \mathrm{~mol} \cdot \mathrm{L}^{-1} \cdot \mathrm{min}^{-1}$.

The formation of $\mathrm{Fe}(\mathrm{II})$ at the same time is followed by complexometry and reveal weak formation in the beginning of the reaction, whereas for long time the concentration of $\mathrm{Fe}(\mathrm{II})$ grown up.

The generation of $\mathrm{Fe}(\mathrm{II})$ by photochemical reactions of $\mathrm{Fe}(\mathrm{III})$-Cit complex inducing ${ }^{\circ} \mathrm{OH}$ radicals production suggests that citrate in the $\mathrm{Fe}$ (III)-Cit systems simultaneously plays the roles of a carboxylate ligand and a reductant of $\mathrm{Fe}(\mathrm{III})$.

\subsubsection{Effect of $\mathrm{Fe}(\mathrm{III})$-Cit Complex on $m$-Cresol Photodegradation}

(1) Interaction of the Mixture in Dark at Room Temperature. $\mathrm{Fe}(\mathrm{III})$-Cit, with $\mathrm{pKa}=3.3$, undergoes a proteolytic equilibrium between a neutral form and the monohydroxy form 


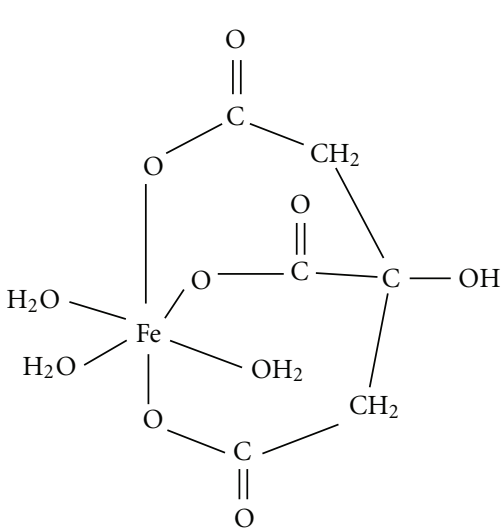

FeL

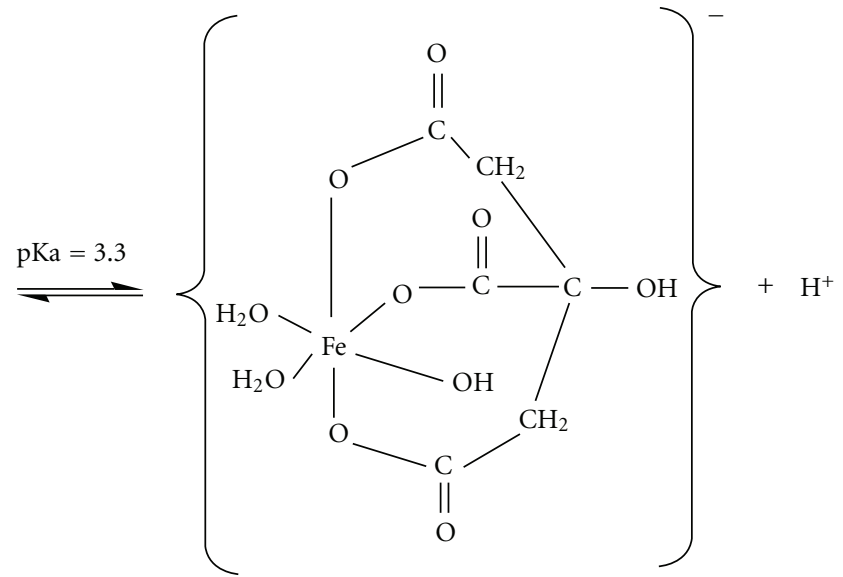

$\mathrm{FeL} \mathrm{OH}^{-}$

Scheme 1: Structure of Fe(III)-Cit complex.

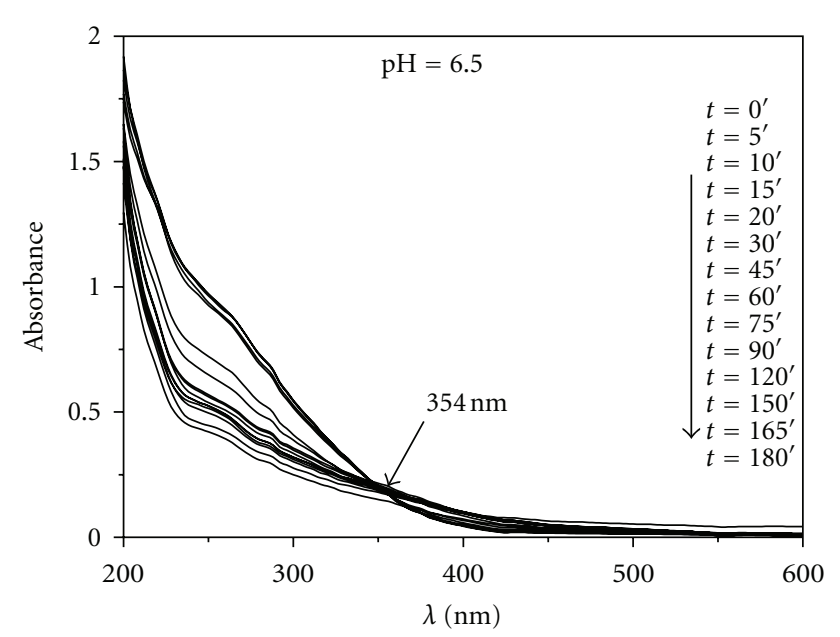

Figure 4: UV-Visible spectra of Fe(III)-Cit complex (0.3 mM) upon irradiation at $365 \mathrm{~nm} . \mathrm{pH}=6.5$.

Scheme 1.Though the absorption of Fe(III)-Cit complex varies with $\mathrm{pH}$, it remains roughly constant at $365 \mathrm{~nm}$ over a large $\mathrm{pH}$ range [7] $\left(\varepsilon=344 \mathrm{M}^{-1} \mathrm{~cm}^{-1}\right)$ from $\mathrm{pH}$ 6.1. In this research, m-cresol was used as a model and target compound to study the capacity of $\mathrm{Fe}(\mathrm{III})$-Cit complexes in the degradation of pollutants.

The UV-visible spectra of $\mathrm{m}$-cresol $(0.1 \mathrm{mM})$ in aqueous solution exhibits maxima at $272 \mathrm{~nm}\left(\varepsilon=1460 \mathrm{M}^{-1} \mathrm{~cm}^{-1}\right)$. Moreover, no detectable absorption is present above $400 \mathrm{~nm}$.

A dark investigation of the system $\mathrm{m}$-cresol/Fe(III)-Cit was performed before studying the photochemical behavior. The mixture $\mathrm{m}$-cresol/Fe(III)-Cit $(0,1 \mathrm{mM}, 0,3 \mathrm{mM})$ was kept in the dark at room temperature.

Figure 6 shows the UV-Visible spectrum of different aqueous solutions freshly prepared.

Under our experimental conditions, no interaction occurs between the components when this mixture ages.

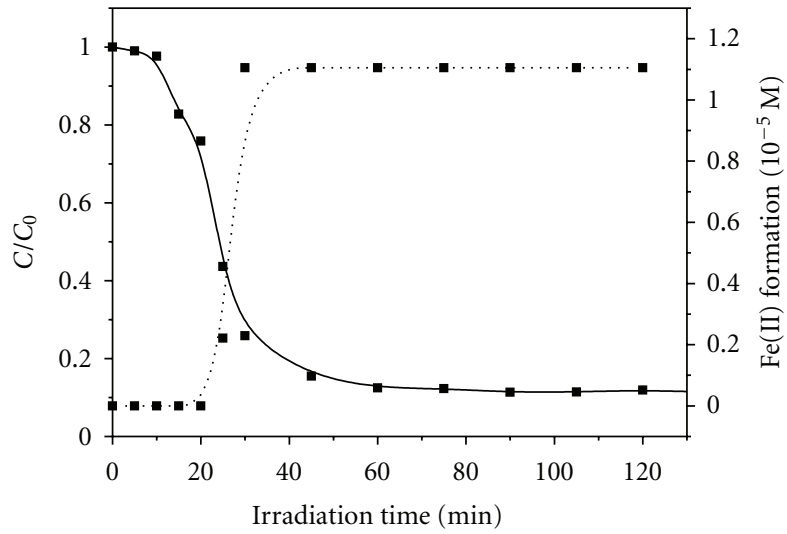

FIgURE 5: Kinetics disappearance of Fe(III)-Cit complex (0.3 mM) and $\mathrm{Fe}(\mathrm{II})$ formation.

(2) Photodegradation of m-Cresol Induced by Fe(III)-Cit Complex. Upon irradiation at $365 \mathrm{~nm}$ of a solution containing a mixture of $\mathrm{m}$-cresol/Fe(III)-Cit $(0.1 \mathrm{mM}, 0.3 \mathrm{mM})$ in the natural conditions of $\mathrm{pH}$ and temperature, there is a decrease in the concentration of $\mathrm{m}$-cresol. The concentration changes were followed by high performance liquid chromatography HPLC. In Figure $7, \mathrm{~m}$-cresol disappears rapidly from the beginning of the reaction. This greatly slows down after 20 minutes of irradiation. This slowdown is explained by deficiency in Fe(III)-Cit complex. Indeed, the complex is $90 \%$ consumed after 30 minutes (insert Figure 7). This is consistent with the kinetics of disappearance of $\mathrm{m}$-cresol maximum obtained after 30 minutes beyond which the concentration of $\mathrm{Fe}$ (II) slowed.

(3) Comparative Study by Means Inducer. The photodegradation of $\mathrm{m}$-cresol $(0.1 \mathrm{mM})$ was studied in this work. The control experiments were carried out in the systems with $0.3 \mathrm{mM} \mathrm{FeClO}_{4}, 0.3 \mathrm{mM}$ Citric Acid, and 0.3 mM Fe(III)-Cit 


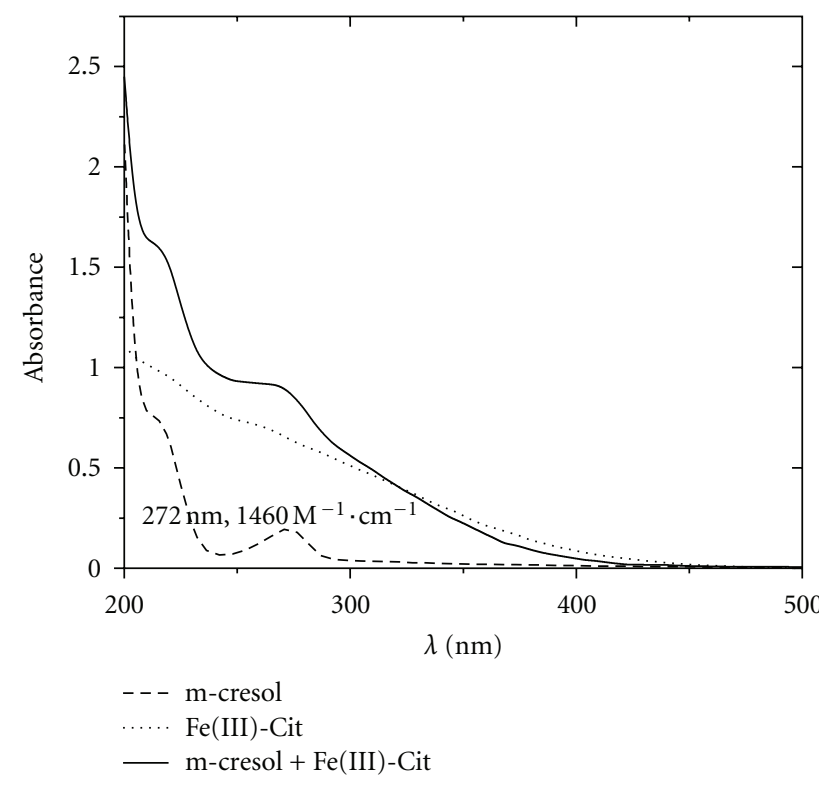

FIGURE 6: Comparing of the UV-Vis absorption spectra of m-cresol $0.1 \mathrm{mM}, \mathrm{Fe}(\mathrm{III})$-Cit $0.3 \mathrm{mM}$ and mixture of $\mathrm{m}$-cresol/Fe(III)-Cit $(0.1 \mathrm{mM}, 0.3 \mathrm{mM})$.

complex. The dark reaction was carried out to keep the mixture of m-cresol, $\mathrm{Fe}(\mathrm{III})$, and Citrate in the dark. The results are presented in Figure 8.

In the single system of $\mathrm{m}$-cresol under UV irradiation, the photodegradation efficiency of $m$-cresol reached $30 \%$ in $6 \mathrm{~h}$. Therefore, direct UV irradiation is insufficient to decompose this pollutant. While in the two-component system with $\mathrm{m}$-cresol and citric acid, the photodegradation efficiency at the same time is $34 \%$. A small increase in the degradation efficiency of $\mathrm{m}$-cresol is attributed to the possible oxidants (e.g., $\mathrm{H}_{2} \mathrm{O}_{2}$ ) that are produced by photolysis of citric acid ([20] and references therein):

$$
\begin{gathered}
\mathrm{H}_{3} \mathrm{Cit}+\mathrm{O}_{2}+h \nu \longrightarrow \mathrm{H}_{3} \mathrm{Cit}^{\bullet+}+\mathrm{O}_{2}^{\bullet-} \\
\mathrm{H}^{+}+\mathrm{O}_{2}^{\cdot-} \longleftrightarrow \mathrm{HO}_{2}{ }^{\bullet},
\end{gathered}
$$

where $\mathrm{k}=6.32 \times 10^{4} \mathrm{~mol} \cdot \mathrm{L}^{-1} \cdot \mathrm{s}^{-1}[37]$

$$
2 \mathrm{HO}_{2} \cdot \longrightarrow \mathrm{H}_{2} \mathrm{O}_{2}+\mathrm{O}_{2},
$$

where $\mathrm{k}=8.3 \times 10^{5} \mathrm{~mol} \cdot \mathrm{L}^{-1} \cdot \mathrm{s}^{-1}[37]$.

The produced $\mathrm{H}_{2} \mathrm{O}_{2}$ is induced by UV irradiation to generate ${ }^{\bullet} \mathrm{OH}\left[38\right.$ ] and then $\mathrm{m}$-cresol is oxidized by ${ }^{\bullet} \mathrm{OH}$

$$
\mathrm{H}_{2} \mathrm{O}_{2}+h v \longrightarrow 2^{\bullet} \mathrm{OH}(<300 \mathrm{~nm})
$$

$$
\text { Pollutant }+{ }^{\bullet} \mathrm{OH} \longrightarrow \text { products (unknown) }
$$

In the catalytic system containing m-cresol and $\mathrm{Fe}(\mathrm{III})$, the photodegradation efficiency is increased to $22 \%$ in $6 \mathrm{~h}$. This may be due to the formation of $\cdot \mathrm{OH}$ radical from

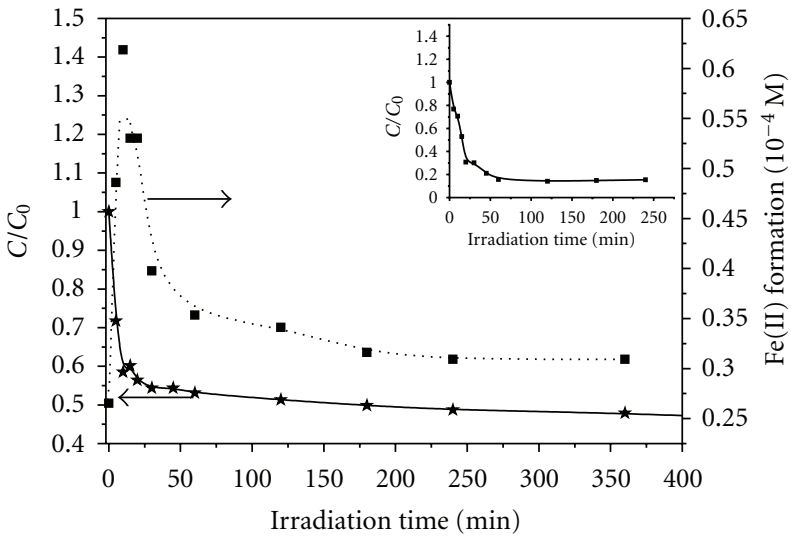

Figure 7: Kinetics disappearance of $\mathrm{m}$-cresol in the mixture $\mathrm{m}$-cresol/Fe(III)-Cit $(0.1 \mathrm{mM}, 0.3 \mathrm{mM})$ upon irradiation at $\lambda_{\text {irradiation }}=365 \mathrm{~nm}$ and $\mathrm{Fe}(\mathrm{II})$ formation. Inset displays disappearance of $\mathrm{Fe}(\mathrm{III})$-Cit complex in the mixture m-crésol/Fe(III)-Cit$(0.1 \mathrm{mM} / 0.3 \mathrm{mM})$.

photoreduction of $\mathrm{Fe}(\mathrm{III})$ and $\mathrm{m}$-cresol is decomposed according to

$$
[\mathrm{Fe}(\mathrm{OH})]^{2+}+\mathrm{hv} \longrightarrow \mathrm{Fe}(\mathrm{II})+{ }^{\bullet} \mathrm{OH}
$$

where $\mathrm{k}=6.3 \times 10^{-4} \mathrm{~mol} \cdot \mathrm{L}^{-1} \cdot \mathrm{s}^{-1}[39]$.

As is reported by Wu and Deng [40], in the acidic medium, there are at least four different species of $\mathrm{Fe}(\mathrm{III})$ ions in aqueous solution: $\mathrm{Fe}(\mathrm{III}) ;[\mathrm{Fe}(\mathrm{OH})]^{2+} ;\left[\mathrm{Fe}(\mathrm{OH})_{2}\right]^{+}$; the dimer $\left[\mathrm{Fe}_{2}(\mathrm{OH})_{2}\right]^{4+}$. The quantum yield of ${ }^{\bullet} \mathrm{OH}$ produced from the photolysis of $[\mathrm{Fe}(\mathrm{OH})]^{2+}$ is much higher than that of the other species. In the m-cresol/Fe(III)-Cit system the photodegradation efficiency reaches $52 \%$ in $6 \mathrm{~h}$. It may be attributed to the formation of hydroxyl radicals through a photo-Fenton reaction system. Although ${ }^{\bullet} \mathrm{OH}$ radicals could be produced by the direct photolysis of Fe(III) and citric acid, the amount of the radicals produced was less than in the $\mathrm{Fe}(\mathrm{III})$-Cit system [41].

Effect of $p H$ on m-Cresol Photodegradation. Experiments were carried out to study the $\mathrm{pH}$ effect on the photodegradation of $\mathrm{m}$-cresol $0.1 \mathrm{mM}$ in the solution with $0.3 \mathrm{mM}$ of $\mathrm{Fe}(\mathrm{III})$-Cit complex. $\mathrm{pH}$ was adjusted to desired value. Figure 9 shows that the optimal photodegradation efficiency was observed at acidic medium. More than $71 \%$ of the m-cresol degraded at $\mathrm{pH}=2.86$, but only $59 \%$ at $\mathrm{pH}=3.5$ and $54 \%$ at $\mathrm{pH}=6.44$ after $6 \mathrm{~h}$ of irradiation. The photodegradation efficiency slowed down when the value of $\mathrm{pH}$ increase. This fact can be attributed to the acidic condition approving the photocycling of $\mathrm{Fe}(\mathrm{III}) / \mathrm{Fe}$ (II) and the formation of active oxygen species, which was the main cause for the degradation of m-cresol.

$\mathrm{Fe}$ (II) Formation. Fe(II) concentration was also determined at the same time. Results presents also a strong effect of $\mathrm{pH}$ on the formation of $\mathrm{Fe}(\mathrm{II})$ species. Low $\mathrm{pH}$ is favorable for the formation of $\mathrm{Fe}(\mathrm{II})$, nevertheless, for the relative 


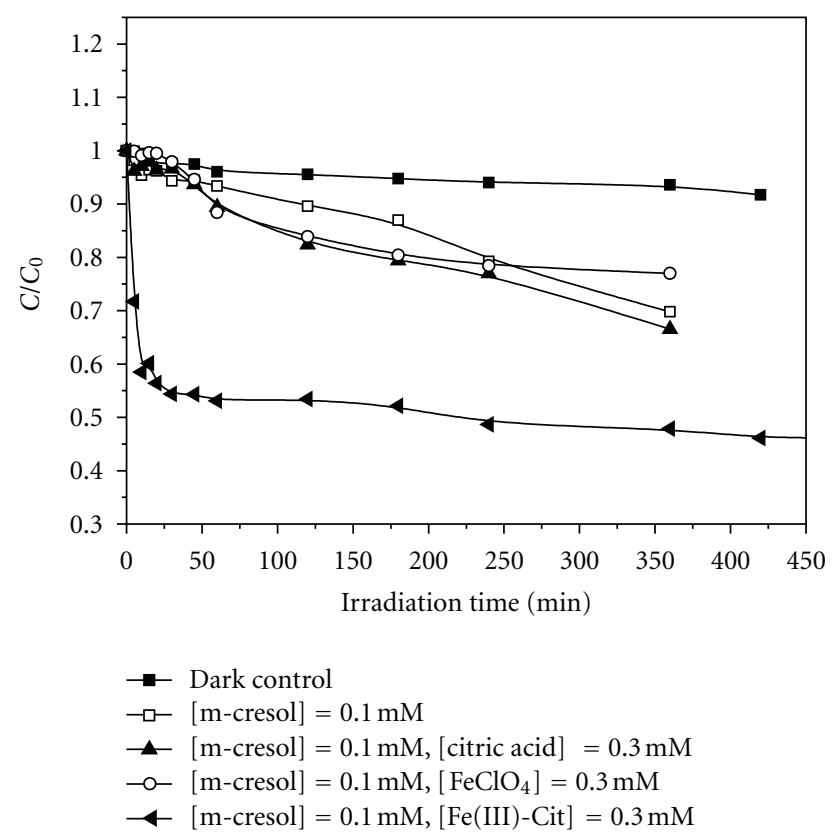

Figure 8: Photodegradation of $\mathrm{m}$-cresol $(0.1 \mathrm{mM})$ in different systems upon irradiation at $\lambda_{\text {irradiation }}=365 \mathrm{~nm}$ : $\square \mathrm{m}$-cresol only; m-cresol-citric acid; $\Delta$ m-cresol- $-\mathrm{FeClO}_{4} ; \boldsymbol{\Delta}$ m-cresol/Fe(III)-Cit complex.

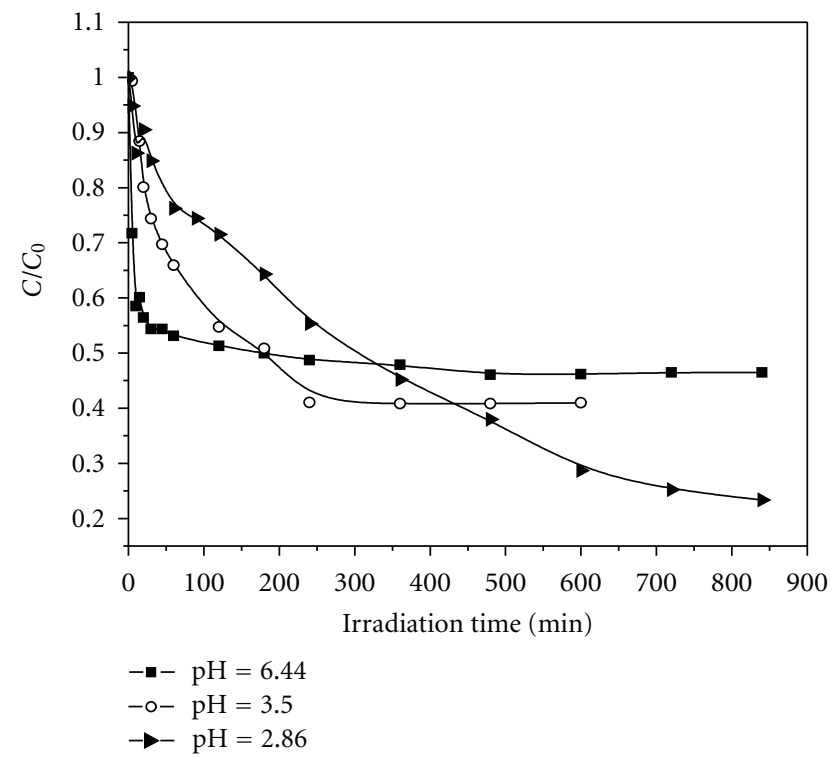

Figure 9: $\mathrm{m}$-cresol disappearance in the mixture upon irradiation $(365 \mathrm{~nm})$ at different $\mathrm{pH}: \mathbf{p H}=6.44, \bigcirc \mathrm{pH}=3.50, \boldsymbol{p H}=2.86$.

higher $\mathrm{pH}$ value, the concentration of iron species was slower (Figure 10).

Lower concentration of $\mathrm{Fe}$ (II) in the solution and lower formation of radicals species $\left({ }^{\bullet} \mathrm{OH}\right)$, causes the photodegradation efficiency of m-cresol to slow down.

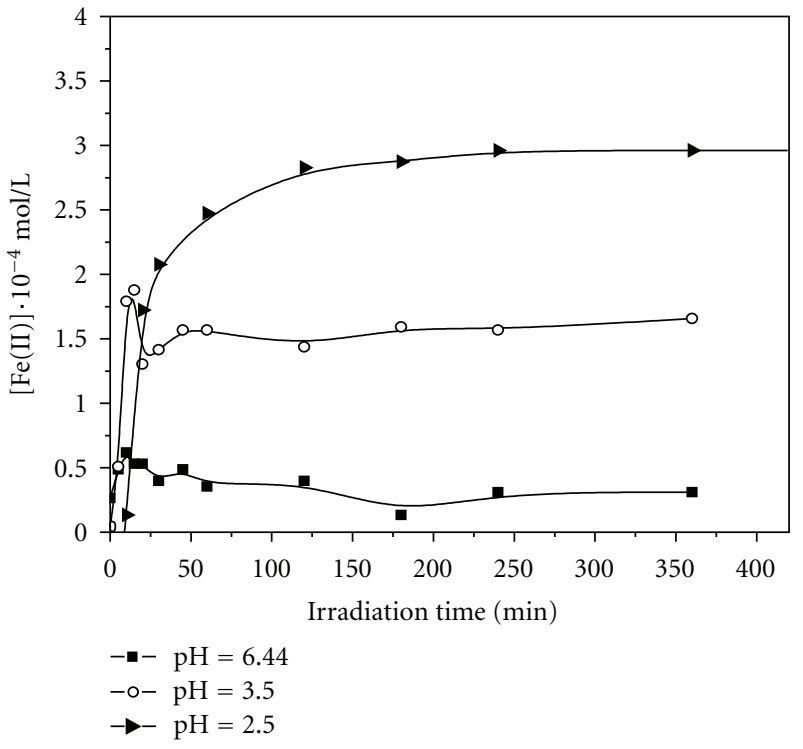

Figure 10: $\mathrm{Fe}$ (II) formation in the mixture m-cresol/Fe(III)-Cit $(0.1 \mathrm{mM}, 0.3 \mathrm{mM})$ upon irradiation at $\lambda_{\text {irradiation }}=365 \mathrm{~nm} \mathbf{p H}=$ 6.44, $\bigcirc \mathrm{pH}=3.50, \triangleright \mathrm{pH}=2.86$.

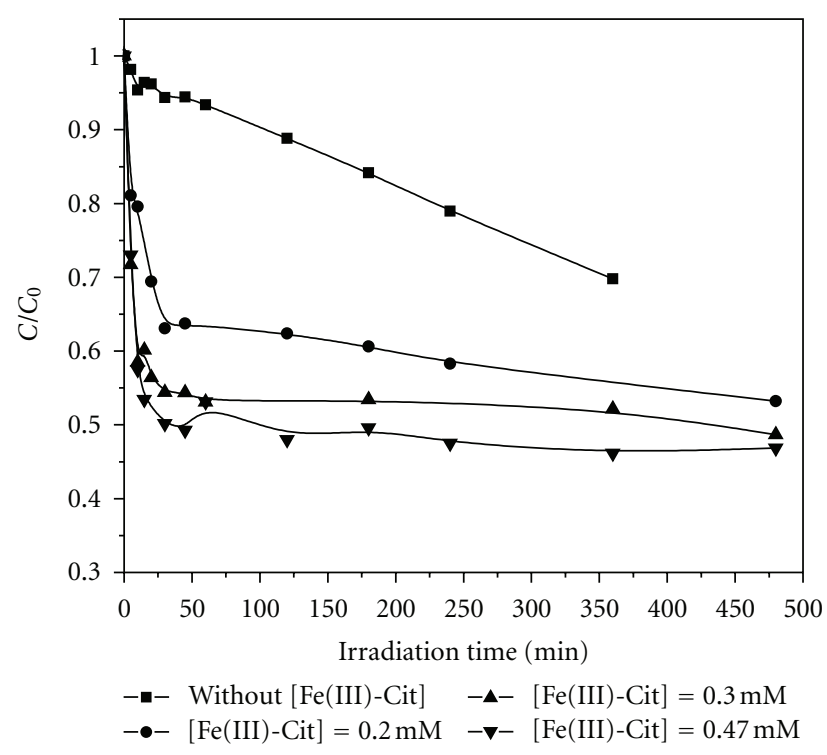

FIGURE 11: $\mathrm{m}$-cresol disappearance in the mixture up on irradiation $(365 \mathrm{~nm})$ at different complex concentrations: $\mathbf{W}$ Without Fe(III)$\mathrm{Cit}, \bullet[\mathrm{Fe}(\mathrm{III})-\mathrm{Cit}]=0.2 \mathrm{mM}, \boldsymbol{\Delta}[\mathrm{Fe}(\mathrm{III})$-Cit $]=0.3 \mathrm{mM}, \boldsymbol{\nabla}[\mathrm{Fe}(\mathrm{III})-$ $\mathrm{Cit}]=0.47 \mathrm{mM}$.

Effect of the Complex Concentration on m-Cresol Photodegradation. Experiments were carried out to study the effect of $\mathrm{Fe}(\mathrm{III})$-Cit concentration on the photodegradation of $\mathrm{m}$ cresol. The initial concentrations of Fe(III)-Cit complex used in the work are $0.2,0.3$ and $0.47 \mathrm{mM}$. The solutions contain $0.1 \mathrm{mM}$ of m-cresol with an initial $\mathrm{pH}$ value equal to 6.44. The results shown in Figure 11 illustrate that photodegradation efficiency of $\mathrm{m}$-cresol increased with the increase of $\mathrm{Fe}$ (III)-Cit complex concentration. In fact, after 


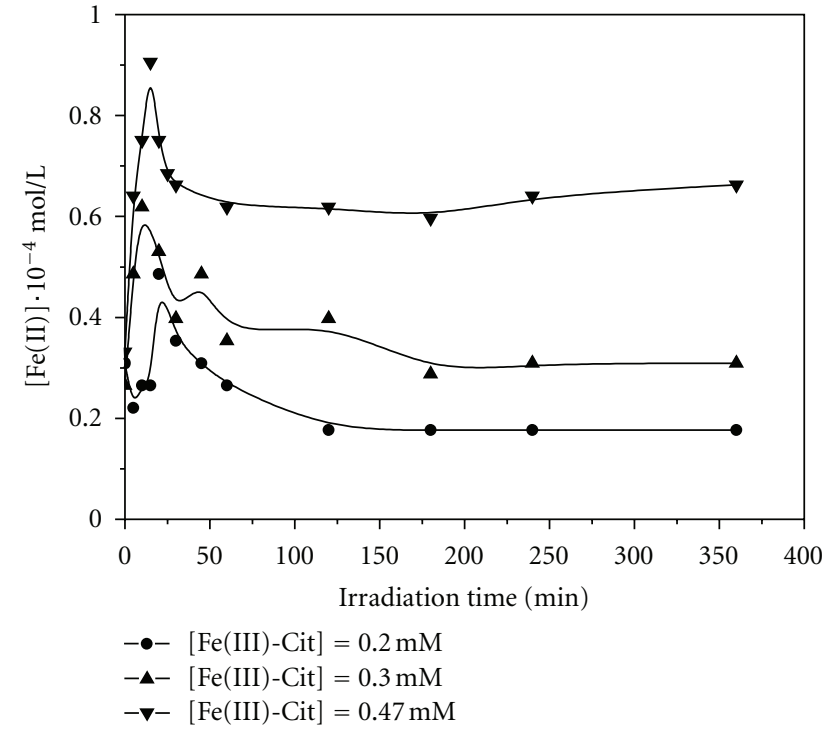

Figure 12: $\mathrm{Fe}$ (II) formation during $\mathrm{m}$-cresol photodegradation $(0.1 \mathrm{mM})$ in the presence of different complex concentrations. $\lambda_{\text {irradiation }}=365 \mathrm{~nm}:-[\mathrm{Fe}(\mathrm{III})-\mathrm{Cit}]=0.2 \mathrm{mM}, \boldsymbol{\Delta}[\mathrm{Fe}(\mathrm{III})-\mathrm{Cit}]=$ $0.3 \mathrm{mM}, \boldsymbol{\nabla}[\mathrm{Fe}(\mathrm{III})-\mathrm{Cit}]=0.47 \mathrm{mM}$.

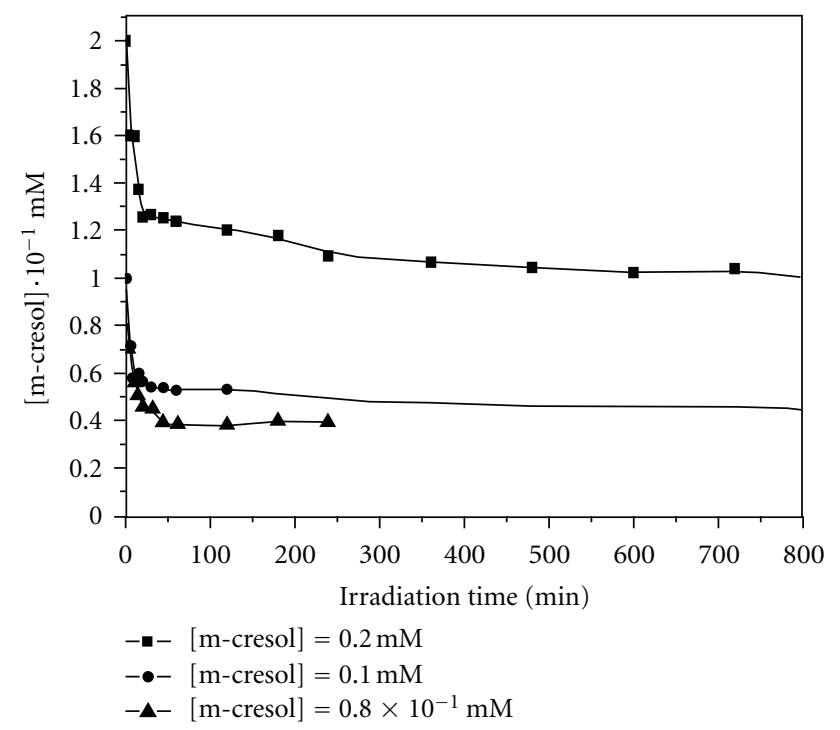

FIGURE 13: $\mathrm{m}$-cresol disappearance in the mixture upon irradiation $(365 \mathrm{~nm})$ at different $\mathrm{m}$-cresol concentrations: $[\mathrm{m}$-cresol $]=0.2 \times$ $\mathrm{mM}, \bullet[\mathrm{m}$-cresol $]=0.1 \mathrm{mM}, \boldsymbol{\Delta}[\mathrm{m}$-cresol $]=0.8 \times 10^{-1} \mathrm{mM}$.

$8 \mathrm{~h}$ irradiation, $54 \%, 52 \%$, and $47 \%$ of the $\mathrm{m}$-cresol had disappeared in the solution with $0.47,0.3$ and $0.2 \mathrm{mM}$ of the $\mathrm{Fe}$ (III)-Cit complex, respectively. It is clearly apparent that the increase in disappearance was roughly proportional to the concentration complex. In addition, there was no further m-cresol disappearance when complex concentrations were increased up to $0.47 \mathrm{mM}$.

In fact, if the complex concentration is too high, competition reaction will strongly exist between the organic substances (acid carboxylic and $\mathrm{m}$-cresol) in aqueous solution.

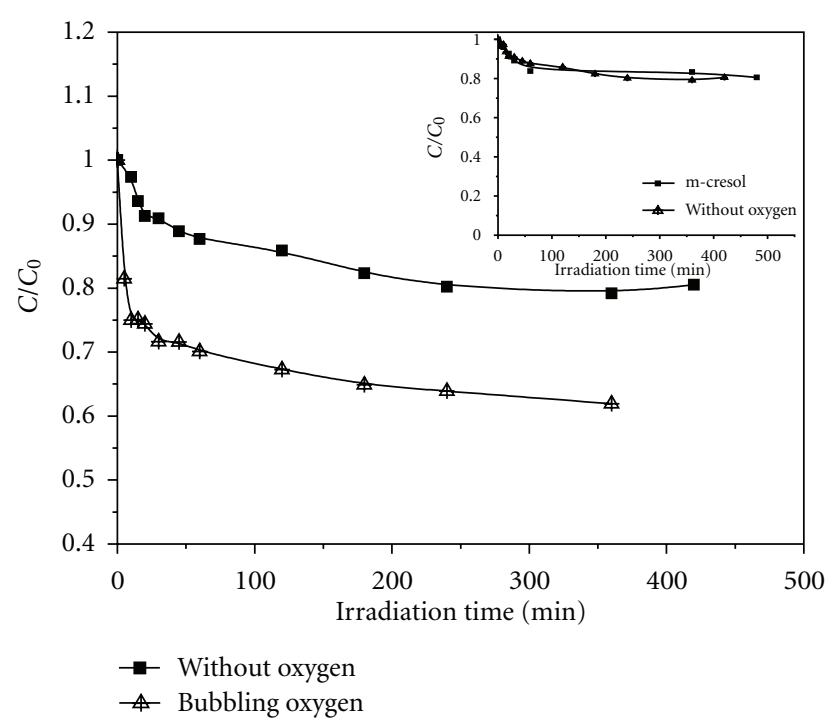

FIGURE 14: $\mathrm{m}$-cresol disappearance in the mixture upon irradiation (365 nm): $\triangle$ bubbling $\mathrm{O}_{2}, \boldsymbol{\square}$ without $\mathrm{O}_{2}$. Inset displays: $\mathbf{\square}$ photolysis of $\mathrm{m}$-cresol, $\boldsymbol{\Delta}$ photodegradation of $\mathrm{m}$-cresol in the absence of oxygen.

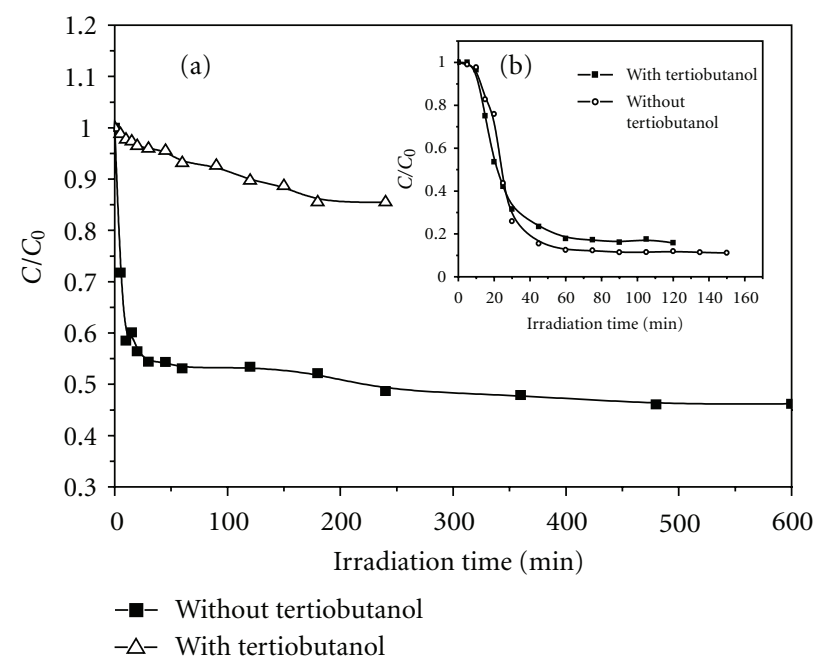

Figure 15: Photodegradation of $\mathrm{m}$-cresol in the mixture $\mathrm{m}$ cresol/Fe(III)-Cit $(0.1 \mathrm{mM}, 0.3 \mathrm{mM})$ upon irradiation at $\lambda_{\text {irradiation }}=$ $365 \mathrm{~nm}$. $\triangle$ with tertiobutanol, $\square$ without tertiobutanol. Inset displays photodegradation of $\mathrm{Fe}(\mathrm{III})$-Cit $(0.3 \mathrm{mM}) . \diamond$ with tertiobutanol, $\square$ without tertiobutanol.

Less active species is available for the degradation of $\mathrm{m}$ cresol.

It is important to note that during the irradiation process, $\mathrm{Fe}$ (III) has been photoreduced to $\mathrm{Fe}$ (II) and the reaction then continues (photocatalytic cycle $\mathrm{Fe}(\mathrm{III}) / \mathrm{Fe}(\mathrm{II})$ consuming $\mathrm{Fe}(\mathrm{II})$ and formed ${ }^{\circ} \mathrm{OH}$, which is the main reason for $\mathrm{m}^{-}$ cresol degradation.

$\mathrm{Fe}$ (II) Formation. By examining Figure 12 which presents the photogeneration of $\mathrm{Fe}(\mathrm{II})$ during the experiments two 
TABLE 1: Half-lives of $\mathrm{m}$-cresol in various initial concentrations.

\begin{tabular}{ll}
\hline $\begin{array}{l}\text { Concentration of m-cresol } \\
(\mathrm{mM})\end{array}$ & $t_{1 / 2}(\mathrm{~min})$ \\
\hline 0.2 & 770 \\
0.1 & 180 \\
$0,8 \times 10^{-1}$ & 47 \\
\hline
\end{tabular}

remarks will be highlighted: with higher concentration of complex, higher concentration of Fe(II) in the solution, and higher formation of radicals species, thus, the photodegradation efficiency of $\mathrm{m}$-cresol is important. An additional excess in complex did not provide any additional increase in terms of pollutant removal.

Effect of m-Cresol Concentration on the Kinetic Photodegradation. Experiments were carried out under different $\mathrm{m}$ cresol initial concentrations in the $\mathrm{Fe}(\mathrm{III})$-Cit system at natural $\mathrm{pH}$. As is shown in Figure 13, the photodegradation efficiency of $\mathrm{m}$-cresol decreased with the increase of $\mathrm{m}$-cresol concentration from $0.8 \times 10^{-1}$ ) to $0.2 \mathrm{mM}$.For different initial concentrations of $\mathrm{m}$-cresol, we calculated the half-lives $\left(t_{1 / 2}\right)$. Results were presented in Table 1.

Effect of Oxygen. Oxygen is another very important factor in the photochemical reactions. So it is necessary to study its effect on the photodegradation of $\mathrm{m}$-cresol. The mixture $\mathrm{m}$-cresol/Fe(III)-Cit $(0.1 \mathrm{mM}, 0.3 \mathrm{mM})$ was carried out in deaerated and oxygen saturated solution separately. The results presented in Figure 14 illustrate that oxygen has a strong effect on the reaction. The increase in oxygen in solution enhances the rate of reaction and then the photodegradation efficiency of $\mathrm{m}$-cresol is improved.

These results are in good agreement with some authors $[36,42]$ who explain this phenomenon by generation of reactive species $\left(\mathrm{O}_{2}{ }^{\cdot-}, \mathrm{H}_{2} \mathrm{O}_{2}\right.$, and then $\left.{ }^{\circ} \mathrm{OH}\right)$ in aqueous solutions in the presence of oxygen. In contrast, the $\mathrm{m}$-cresol disappearance (less than 20\%) seems to be related to the photolysis of $\mathrm{m}$-cresol in aqueous solution at $365 \mathrm{~nm}$ (insert Figure 14).

Effect of Tertiobutanol. Contrary to $\mathrm{Fe}(\mathrm{III})$-Cit disappearance that was insensitive to tertiobutanol, the degradation of $\mathrm{m}$-cresol in the mixture $\mathrm{m}$-cresol/Fe(III)-Cit $(0.1 \mathrm{mM}$, $0.3 \mathrm{mM}$ ) was strongly inhibited in presence of tertiobutanol (Figure 15). This inhibition confirms the involvement of radical $\cdot \mathrm{OH}$ in degradation of $\mathrm{m}$-cresol induced by the complex Fe(III)-Cit.

\section{Conclusion}

In this work, the $\mathrm{Fe}(\mathrm{III})$-Cit/UVA photocatalytic system is studied to remove $\mathrm{m}$-cresol from water. We demonstrated that $\mathrm{Fe}(\mathrm{III})$ were complexed by citric acid, the formation and composition of $\mathrm{Fe}$ (III)-Cit complex was first studied. With a stoichiometry $2: 1$ and the value of stability constant being $\beta=6.3 \times 10^{19}$, this type of complexes could be formed in the natural aquatic environment due to the presence of citric acid and iron. Thus, under irradiation, the photolysis of Fe(III)Cit complexes could represent the source of active oxygen radicals.

Upon irradiation at $365 \mathrm{~nm}, \mathrm{Fe}(\mathrm{III})$-Cit complex could enhance the photooxidation of $\mathrm{m}$-cresol in the aqueous solution. The photodegradation efficiency relied on the $\mathrm{pH}$, oxygen, $\mathrm{Fe}$ (III)-Cit complex, and m-cresol concentrations. All these factors have an impact on the concentration of $\mathrm{Fe}$ (II) formation and $\mathrm{m}$-cresol disappearance and also on the kinetic of $\mathrm{m}$-cresol degradation. High degradation efficiency was obtained at high concentrations of Fe(III)-Cit and at low $\mathrm{pH}=2.86$. However, the photodegradation efficiency was decreased with the increase of initial $\mathrm{m}$-cresol concentration. The photodegradation efficiency of $\mathrm{m}$-cresol is much higher in aerated solution than in the deaerated solution. Oxygen is a crucial parameter for formation of reactive species, such as $\left(\mathrm{O}_{2}{ }^{\cdot-}\right.$ and $\left.{ }^{\bullet} \mathrm{OH}\right)$ in the aqueous solution. Based on all these information obtained above, ${ }^{\bullet} \mathrm{OH}$ is considered as the most important reactive species that plays the dominating role in the photodegradation process of $\mathrm{m}$-cresol induced by $\mathrm{Fe}(\mathrm{III})$-Cit complex. These observations promote much interest in the understanding of the mechanisms responsible for the degradation of $\mathrm{m}$-cresol in the $\mathrm{Fe}(\mathrm{III})$-Cit system. This work could help us to fully understand the photoreaction processes concerning $\mathrm{Fe}(\mathrm{III})$-Cit complex for the degradation of pollutants in the aquatic environment under irradiation.

\section{References}

[1] X. Domènech, W. Jardim, and M. Litter, "Tecnologias avanzadas de oxidacion para la eliminacion de contaminantes," in Eliminacion de Contaminantes por Fotocatalisis Heterogènea. Texto Colectivo Elaborado por la Red CYTED VIII-G, M. A. Blesa y and B. Sanchez Cabrero, Eds., pp. 7-34, Ediciones CIEMAT, Madrid, Spain, 2004.

[2] M. I. Litter, "Introduction to photochemical advanced oxidation processes for water treatment," in The Handbook of Environmental Chemistry, P. Boule, D. W. Bahnemann, and P. K. J. Robertson, Eds., vol. 2/M of Environmental Photochemistry Part II, pp. 325-366, Springer, Berlin, Germany, 2005.

[3] M. Fukushima and K. Tatsumi, "Photocatalytic reaction of iron-humate complex and its effect on the removal of organic pollutant from the aqueous solution," Toxicological and Environmental Chemistry, vol. 73, pp. 103-116, 1999.

[4] B. A. Southworth and B. M. Voelker, "Hydroxyl radical production via the photo-fenton reaction in the presence of fulvic acid," Environmental Science and Technology, vol. 37, no. 6, pp. 1130-1136, 2003.

[5] B. C. Faust and R. G. Zepp, "Photochemistry of aqueous iron(III)-polycarboxylate complexes: roles in the chemistry of atmospheric and surface waters," Environmental Science and Technology, vol. 27, no. 12, pp. 2517-2522, 1993.

[6] M. J. Milewska, "Citric acid-its natural and synthetic derivatives," Zeitschrift für Chemie, vol. 28, no. 6, pp. 204-211, 1988.

[7] N. Quici, M. E. Morgada, R. T. Gettar, M. Bolte, and M. I. Litter, "Photocatalytic degradation of citric acid under different conditions: $\mathrm{TiO}_{2}$ heterogeneous photocatalysis against homogeneous photolytic processes promoted by $\mathrm{Fe}$ (III) and $\mathrm{H}_{2} \mathrm{O}_{2}$," Applied Catalysis B, vol. 71, no. 3-4, pp. 117-124, 2007. 
[8] A. E. Martell and R. M. Smith, Critical Stability Constants, vol. 3, Plenum Press, New York, NY, USA, 1974.

[9] M. Simic, P. Neta, and E. Hayon, "Pulse radiolysis of aliphatic acids in aqueous solutions. II. Hydroxy and polycarboxylic acids," Journal of Physical Chemistry, vol. 73, no. 12, pp. 4214 4219, 1969.

[10] G. P. Laroff and R. W. Fessenden, " ${ }^{13} \mathrm{C}$ hyperfine interactions in radicals from some carboxylic acids," The Journal of Chemical Physics, vol. 55, no. 10, pp. 5000-5008, 1971.

[11] H. Zeldes and R. Livingston, "Paramagnetic resonance study of liquids during photolysis. XI. Citric acid and sodium citrate in aqueous solution," Journal of the American Chemical Society, vol. 93, no. 5, pp. 1082-1085, 1971.

[12] A. Comel and G. Guiochon, "The chemical composition of mixed wastes: analysis of the photolysis products of organic ligands," Journal of Radioanalytical and Nuclear Chemistry, vol. 181, no. 2, pp. 373-384, 1994.

[13] H. B. Abrahamson, A. B. Rezvani, and J. G. Brushmiller, "Photochemical and spectroscopic studies of complexes, of iron(III) with citric acid and other carboxylic acids," Inorganica Chimica Acta, vol. 226, no. 1-2, pp. 117-127, 1994.

[14] G. G. Rao and G. Aravamudan, "Analytical applications of the photochemical action of light. Determination of ferric iron by photochemical reduction in the presence of citric and mandelic acids," Analytica Chimica Acta, vol. 13, pp. 328-333, 1955.

[15] W. Feng and D. Nansheng, "Photochemistry of hydrolytic iron (III) species and photoinduced degradation of organic compounds. A minireview," Chemosphere, vol. 41, no. 8, pp. 1137-1147, 2000.

[16] Y. H. Huang, S. T. Tsai, Y. F. Huang, and C. Y. Chen, "Degradation of commercial azo dye reactive Black B in photo/ ferrioxalate system," Journal of Hazardous Materials, vol. 140, no. 1-2, pp. 382-388, 2007.

[17] W. Feng, D. Nansheng, and Z. Yuegang, "Discoloration of dye solutions induced by solar photolysis of ferrioxalate in aqueous solutions," Chemosphere, vol. 39, no. 12, pp. 20792085, 1999.

[18] D. Nansheng, W. Feng, L. Fan, and X. Mei, "Ferric citrateinduced photodegradation of dyes in aqueous solutions," Chemosphere, vol. 36, no. 15, pp. 3101-3112, 1998.

[19] M. R. A. Silva, A. G. Travo, and R. F. P. Nogueira, "Degradation of the herbicide tebuthiuron using solar photo-Fenton process and ferric citrate complex at circumneutral $\mathrm{pH}$," Journal of Photochemistry and Photobiology A, vol. 19, pp. 187-192, 2007.

[20] X. Ou, X. Quan, S. Chen, F. Zhang, and Y. Zhao, "Photocatalytic reaction by $\mathrm{Fe}(\mathrm{III})$-citrate complex and its effect on the photodegradation of atrazine in aqueous solution," Journal of Photochemistry and Photobiology A, vol. 197, no. 2-3, pp. 382388, 2008.

[21] Y. Chen, F. Wu, Y. Lin, N. Deng, N. Bazhin, and E. Glebov, "Photodegradation of glyphosate in the ferrioxalate system," Journal of Hazardous Materials, vol. 148, no. 1-2, pp. 360-365, 2007.

[22] R. A. Larson, M. B. Schlauch, and K. A. Marley, "Ferric ion promoted photodecomposition of triazines," Journal of Agricultural and Food Chemistry, vol. 39, no. 11, pp. 2057-2062, 1991.

[23] C. Catastini, M. Sarakha, G. Mailhot, and M. Bolte, "Iron (III) aquacomplexes as effective photocatalysts for the degradation of pesticides in homogeneous aqueous solutions," Science of the Total Environment, vol. 298, no. 1-3, pp. 219-228, 2002.

[24] G. Mailhot, A. Asif, and M. Bolte, "Degradation of sodium 4dodecylbenzenesulphonate photoinduced by $\mathrm{Fe}(\mathrm{III})$ in aqueous solution," Chemosphere, vol. 41, no. 3, pp. 363-370, 2000.
[25] N. Debbache, K. Djebbar, B. Lavédrine, G. Mailhot, and M. Bolte, "Fe(III) promoted LAS (linear alkylbenzenesulfonate) removal from waters," Chemosphere, vol. 72, no. 3, pp. 457464, 2008.

[26] L. Wang, C. Zhang, F. Wu, and N. Deng, "Photoproduction and determination of hydroxyl radicals in aqueous solutions of Fe(III)-tartrate complexes: a quantitative assessment," Journal of Coordination Chemistry, vol. 59, no. 7, pp. 803-813, 2006.

[27] S. W. Lam, K. Chiang, T. M. Lim, R. Amal, and G. K.-C. Low, "The role of ferric ion in the photochemical and photocatalytic oxidation of resorcinol," Journal of Catalysis, vol. 234, no. 2, pp. 292-299, 2005.

[28] D. Zhou, F. Wu, N. Deng, and W. Xiang, "Photooxidation of bisphenol a (BPA) in water in the presence of ferric and carboxylate salts," Water Research, vol. 38, no. 19, pp. 41074116, 2004.

[29] A. Safarzadeh-Amiri, J. R. Bolton, and S. R. Cater, "Ferrioxalate-mediated photodegradation of organic pollutants in contaminated water," Water Research, vol. 31, no. 4, pp. 787798, 1997.

[30] E. Rodríguez, M. Mimbrero, F. J. Masa, and F. J. Beltrán, "Homogeneous iron-catalyzed photochemical degradation of muconic acid in water," Water Research, vol. 41, no. 6, pp. 1325-1333, 2007.

[31] H. B. Abrahamson, A. B. Rezvani, and J. G. Brushmiller, "Photochemical and spectroscopic studies of complexes, of iron(III) with citric acid and other carboxylic acids," Inorganica Chimica Acta, vol. 226, no. 1-2, pp. 117-127, 1994.

[32] Y. Zuo, "Kinetics of photochemical/chemical cycling of iron coupled with organic substances in cloud and fog droplets," Geochimica et Cosmochimica Acta, vol. 59, no. 15, pp. 31233130, 1995.

[33] Y. Zuo, "Kinetics of photochemical/chemical cycling of iron coupled with organic substances in cloud and fog droplets," Geochimica et Cosmochimica Acta, vol. 59, no. 15, pp. 31233130, 1995.

[34] S. Kavlak, H. K. Can, and A. Güner, "Interaction of poly(maleic anhydride-alt-acrylic acid) with rransition metal cations, $\mathrm{Ni}^{2+}, \mathrm{Cu}^{2+}$, and $\mathrm{Cd}^{2+}$ : a study by UV-Vis spectroscopy and viscosimetry," Journal of Applied Polymer Science, vol. 92, no. 4, pp. 2698-2705, 2004.

[35] M. L. Hamlaoui, K. Vlassenko, and D. Messadi, "Constantes de stabilité des complexes de quelques métaux de transition avec l'hétéropolyanion non saturé $\left[\mathrm{P}_{2} \mathrm{~W}_{17} \mathrm{O}_{61}\right]^{10-}$," Comptes Rendus de l'Académie des Sciences, vol. 311, pp. 795-798, 1990.

[36] L. Wang, Photodegradation of organique pollutants induced by $\mathrm{Fe}$ (III)-carboxylate complexes in aqueous solutions, Ph.D. thesis, University Balaise Pascal, 2008.

[37] B. H. J. Bielski, D. E. Cabelli, R. L. Arudi, and A. B. Ross, "Reactivity of $\mathrm{HO}_{2} / \mathrm{O}_{2}$ radicals in aqueous solution," Journal of Physical and Chemical Reference Data, vol. 14, pp. 1041-1100, 1985.

[38] S. Parra, V. Sarria, S. Malato, P. Péringer, and C. Pulgarin, "Photochemical versus coupled photochemical-biological flow system for the treatment of two biorecalcitrant herbicides: metobromuron and isoproturon," Applied Catalysis B, vol. 27, no. 3, pp. 153-168, 2000.

[39] B. C. Faust and J. Hoigne, "Photolysis of Fe(III)-hydroxy complexes as sources of $\mathrm{OH}$ radicals in clouds, fog and rain," Atmospheric Environment, vol. 24, no. 1, pp. 79-89, 1990.

[40] F. Wu and N. S. Deng, "Photochemistry of hydrolytic iron (III) species and photoinduced degradation of organic compounds. A minireview," Chemosphere, vol. 41, no. 8, pp. 1137-1147, 2000 . 
[41] J. Guo, Y. Du, Y. Lan, and J. Mao, "Photodegradation mechanism and kinetics of methyl orange catalyzed by $\mathrm{Fe}(\mathrm{III})$ and citric acid," Journal of Hazardous Materials, vol. 186, no. 2-3, pp. 2083-2088, 2011.

[42] O. Abida, G. Mailhot, M. Litter, and M. Bolte, "Impact of iron-complex (Fe(III)-NTA) on photoinduced degradation of 4-chlorophenol in aqueous solution," Photochemical and Photobiological Sciences, vol. 5, no. 4, pp. 395-402, 2006. 


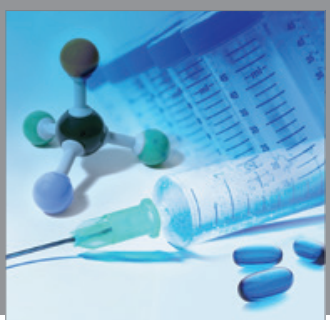

International Journal of

Medicinal Chemistry

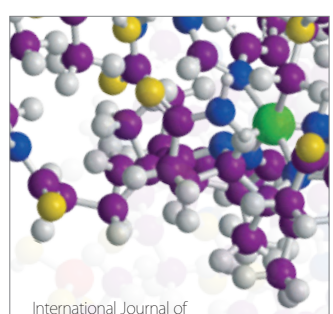

Carbohydrate Chemistry

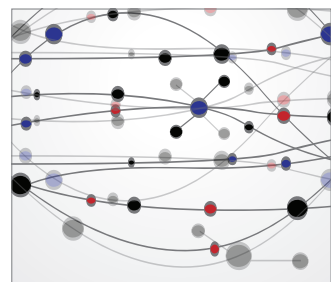

The Scientific World Journal
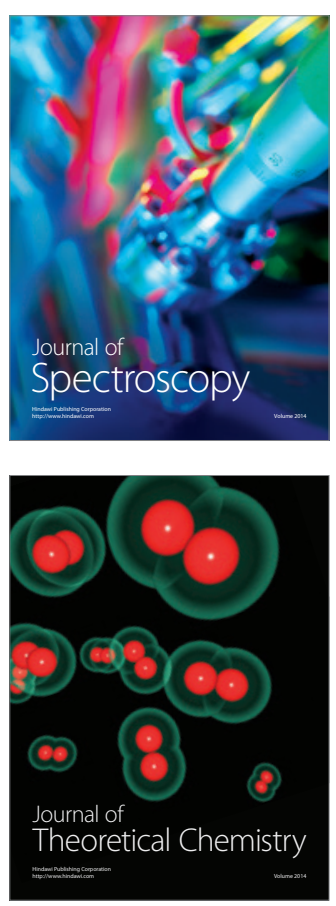
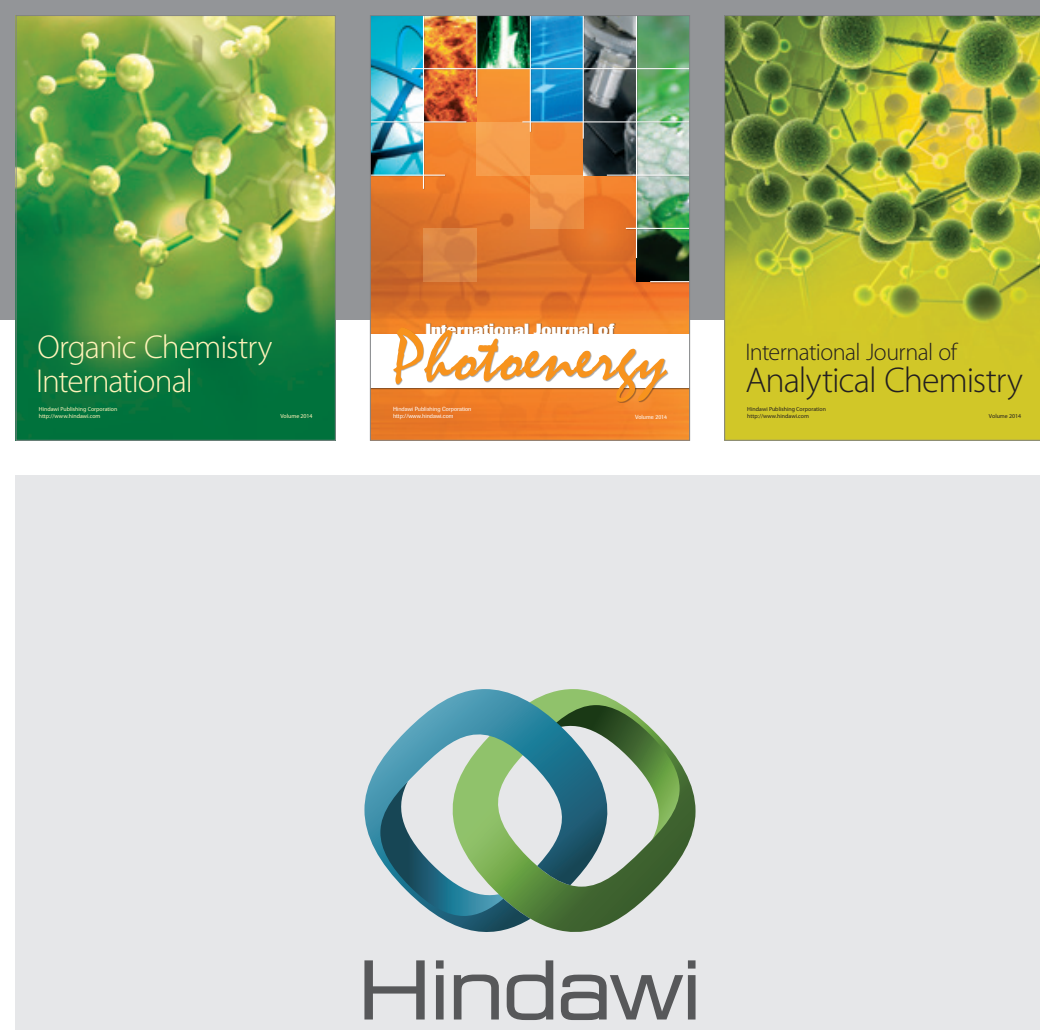

Submit your manuscripts at

http://www.hindawi.com
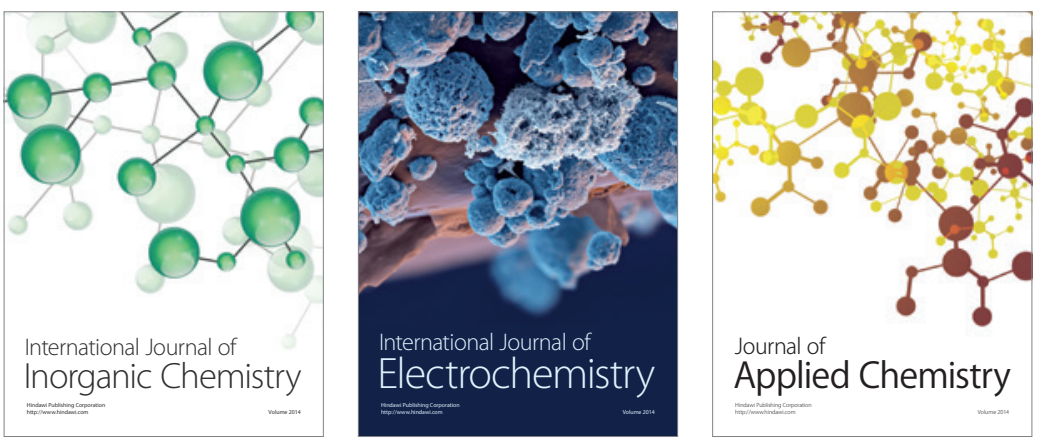

Journal of

Applied Chemistry
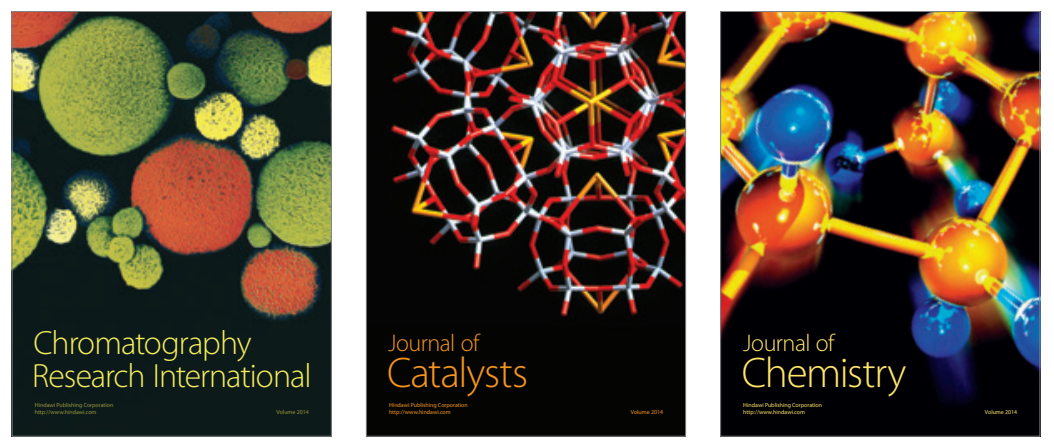
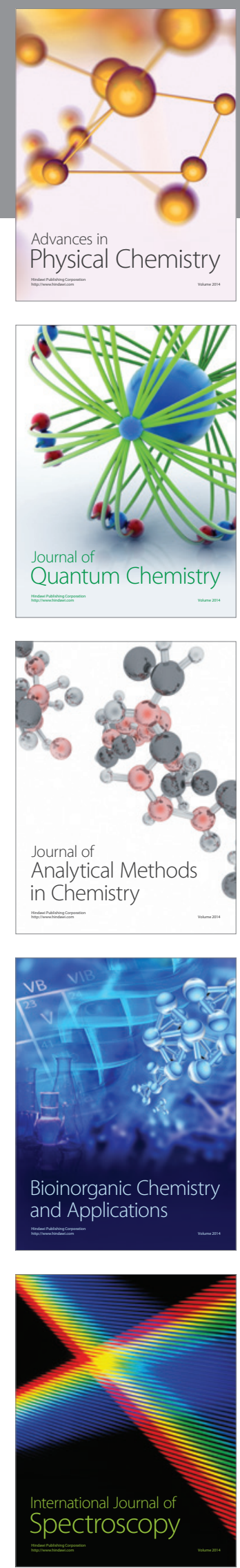